\title{
Opinion
}

\section{Keep the Balance at Home}

\author{
Pascal Kopperschmidt * and Andreas Maierhofer
}

Fresenius Medical Care, Global Research \& Development, DE-61352 Bad Homburg, Germany; andreas.maierhofer@fmc-ag.com

* Correspondence: Pascal.Kopperschmidt@fmc-ag.com

\begin{abstract}
Of the many treatment parameters in hemodialysis care that could be individualised, the dialysate sodium concentration has been identified as a prime candidate for personalisation. Newer hemodialysis machines are equipped with controllers to manage the diffusive balance of sodium between the patient and dialysate. Tailoring of intradialytic sodium transfer is possible in home hemodialysis, where individualization of therapy is particularly appropriate.
\end{abstract}

Keywords: home hemodialysis; sodium management; treatment individualization; sodium control; dialysate prescription; plasma sodium; sodium monitoring; dialysate sodium

The concentration of sodium in dialysate has often been seen as a way of reducing intradialytic symptoms associated with hemodynamic instability, whatever the underlying cause. Dialysis machines are equipped with the capability to 'profile' the dialysate sodium concentration but the therapeutic benefit of pulsatile or similar profiles is unproven. Without a well-founded medical indication, standard sodium profiling should be used with care. Keen and Gotch have proposed that there should be a net-zero diffusive balance of sodium during dialysis of stable patients on a normal diet [1].

Selfcare, whether in the home environment or a limited-care dialysis center, empowers

Citation: Kopperschmidt, P.; Maierhofer, A. Keep the Balance at Home. Kidney Dial. 2022, 2, 80-81.

https://doi.org/10.3390/

kidneydial2010009

Academic Editors: Manfred Hecking, Peter Kotanko and Jochen

G. Raimann

Received: 6 December 2021

Accepted: 1 January 2022

Published: 14 February 2022

Publisher's Note: MDPI stays neutral with regard to jurisdictional claims in published maps and institutional affiliations.

Copyright: (c) 2022 by the authors. Licensee MDPI, Basel, Switzerland. This article is an open access article distributed under the terms and conditions of the Creative Commons Attribution (CC BY) license (https:// creativecommons.org/licenses/by/ $4.0 /)$. in-center hemodialysis may be driven by, among other reasons, a demand for technically intensive care in a less formal environment [2]. Patients having home hemodialysis are a population who are well-educated about their treatment and able to manage many technical issues. For example, they can be encouraged to adjust treatment parameters such as ultrafiltration rate, blood flow rate and session time themselves, within an agreed framework. The need for dialysate sodium adjustments in home therapies has not been discussed up to now, although the situation of home dialysis is ideally suited for individualization of the dialysate composition.

Up to $90 \%$ of patients treated with in-center hemodialysis are subject to a prescribed dialysate sodium concentration of 138-140 mmol/L [3]. The majority of patients tolerate a fixed sodium prescription in standard treatments, not exceeding four hours, quite well, even though individual serum levels may differ significantly [4]. With longer treatment times, larger quantities of dialysate affect multiple body compartments, such that plasma solute concentrations tend to equilibrate close to the dialysate concentration. For example, accumulation in the blood of bicarbonate may lead to symptoms of alkalosis and of sodium may lead to thirst and elevated blood pressure [5]. When patients repeatedly complain about thirst or excessive fluid overload, reduction of the dialysate sodium concentration should be discussed to avoid intradialytic salt overload.

Management of sodium involves the monitoring of sodium calculated from plasma conductivity (SMM) and uses a controller to balance sodium during dialysis (SMC). With automated SMC the patient's serum drives the dialysate sodium concentration during the hemodialysis session [6]. The controller adjusts the mixing of dialysate to balance the transmembrane flow of sodium. In zero-diffusive balancing the net flow of solutes between dialysate and plasma is constantly equilibrated. 
SMC clearly contributes to an individualized treatment prescription by avoiding a large sodium concentration gradient between patient and dialysate. However, for hyponatremic patients representing a pathologic state, equilibrating serum sodium at a low level may result in intradialytic hypotension and other adverse complications. Thus, before applying a net-zero sodium balance the natremic state of the patient should be evaluated.

Patients treated at home who do not have access to a closely linked laboratory should be guided through an incident monitoring phase without SMC. In this phase SMM just monitors the intradialytic sodium mass balance and the pre-dialytic serum sodium level. At clinic visits the collected data should be confirmed by blood laboratory tests. When the predialytic sodium concentration is within the accepted physiological range the monitoring phase ends and SMC can be activated. Typically, zero-diffusive sodium balance should be the method of choice. For a specific medical indication, a defined sodium gap between serum and dialysate can be beneficial.

The delivery of pre-dialytic serum sodium levels by SMM in each treatment provides a very useful tool to promptly identify overhydration associated with rapid loss of muscle mass [7]. Significant changes in natremia may be noticed before the situation becomes severe and appropriate countermeasures can be applied in time. Patients who dialyze at home should be advised to monitor their pre-dialysis serum sodium values and contact their clinician immediately when a trend becomes obvious.

Selfcare can be beneficial in ways other than through intradialytic profiling of dialysate solutes. Improved quality of life, treatment autonomy and playing an active role in the therapy design are the main reasons to opt for home treatment. Increasing individualization of treatment at home often accompanies patients growing in self-confidence and experience of managing their own care.

Author Contributions: P.K. and A.M. contributed equally to all aspects of this work. All authors have read and agreed to the published version of the manuscript.

Funding: This research received no external funding.

Institutional Review Board Statement: Not applicable.

Informed Consent Statement: Not applicable.

Data Availability Statement: Not applicable.

Conflicts of Interest: The authors are fulltime employees of Fresenius Medical Care Germany GmbH.

\section{References}

1. Keen, M.L.; Gotch, F.A. The association of the sodium "setpoint" to interdialytic weight gain and blood pressure in hemodialysis patients. Int. J. Artif. Organs 2007, 30, 971-979. [CrossRef] [PubMed]

2. Wilkie, M. Home dialysis-an international perspective. Nephrol. Dial. Transplant. Plus 2011, 4 (Suppl. S3), iii4-iii6. [CrossRef]

3. Hecking, M.; Karaboyas, A.; Saran, R.; Sen, A.; Inaba, M.; Rayner, H.; Hörl, W.H.; Pisoni, R.L.; Robinson, B.M.; Sunder-Plassmann, G.; et al. Dialysate sodium concentration and the association with interdialytic weight gain, hospitalization, and mortality. Clin. J. Am. Soc. Nephrol. 2012, 7, 92-100. [CrossRef] [PubMed]

4. Lindley, E.J. Reducing sodium intake in hemodialysis patients. Semin. Dial. 2009, 22, 260-263. [CrossRef]

5. Movilli, E.; Camerini, C.; Gaggia, P.; Zubani, R.; Feller, P.; Poiatti, P.; Pola, A.; Carli, O.; Valzorio, B.; Cancarini, G. Role of dialysis sodium gradient on intradialytic hypertension: An observational study. Am. J. Nephrol. 2013, 38, 413-419. [CrossRef] [PubMed]

6. Ságová, M.; Wojke, R.; Maierhofer, A.; Gross, M.; Canaud, B.; Gauly, A. Automated individualization of dialysate sodium concentration reduces intradialytic plasma sodium changes in hemodialysis. Artif. Organs 2019, 43, 1002-1013. [CrossRef] [PubMed]

7. Maierhofer, A.P.; Pinto, B.; Wojke, R.; Ponce, P. Conductivity based online estimation of predialytic plasma sodium: Clinical assessment. Nephrol. Dial. Transplant. 2019, 34 (Suppl. S1), gfz106.FP546. [CrossRef] 